\title{
RECENT MEETINGS
}

\section{Summary of the Evolution and Human Behavior Conferences: Ann Arbor, Michigan, April and October 1988}

\author{
Bobbi S. Low \\ Evolution and Human Behavior Program and School of Natural \\ Resources, University of Michigan, Ann Arbor, Michigan
}

Randolph M. Nesse

Evolution and Human Behavior Program and Department of Psychiatry, University of Michigan, Ann Arbor, Michigan

\section{DAWN OF A RENAISSANCE?}

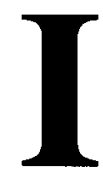

$t$ was Einstein who noted that theory determines what we can see. Today is an exciting time for the study of evolution and human behavior because important shifts in theory have generated new questions and new hypotheses-literally changing what we can see. Twenty-five years ago, the evolutionary theory taught in colleges emphasized the dry bones of history. Worse yet, it seemed unconnected to other endeavors, such as the study of genetics, life histories, or behavior. Rarely were students in evolution classes exposed to the theories of Fisher, Haldane, or Sewell Wright. Biology was fragmented, still fleeing from the misconceptions of vitalism and trying to come to terms with Popperian criticisms. The advances of molecular genetics and physiology were seen by many as the core of "solid" biology.

In this climate, two seminal events went little noticed. The first was William Hamilton's (1964) elucidation of kin selection, which provided a selective basis for understanding costly cooperation. It explained how al-

Received April 13, 1989; accepted April 13, 1989.

Address reprint requests to: Bobbi S. Low, The University of Michigan, 142 Dana Bldg., School of Natural Resources, Ann Arbor, MI 48109-1115. 
truism could evolve through natural selection, if altruists and the recipients of their benefits share genes identical by descent. The second was the 1966 publication of George Williams' Adaptation and Natural Selection. In a few succinct pages, this book analyzed misconceptions and dissected thorny problems, including the central one of the relative potency of selection at different levels. Williams made clear how the evolution of behavior could best be explored by focusing on the effects on the fitness of the individual (and genetic lines), rather than on the benefits to groups, populations, or species.

These advances made possible the study of functional, "why" questions; previously interesting speculations now becane testable hypotheses. Yet the rates at which these advances were incorporated varied among fields. In particular, the application of selection theory to human behavior has proved more complex than any similar endeavor, and development of the human focus within the field of natural selection and behavior has been fragmented.

Important advances included E. O. Wilson's Sociobiology (1975) and Lumsden and Wilson's (1981) Genes, Mind and Culture, Maynard Smith and Price's (1973) game-theoretic approach, several original works (e.g. 1971, 1972, 1974, 1985) by R. L. Trivers, Dawkins' Selfish Gene (1976) and Blind Watchmaker (1986), R. D. Alexander's Darwinism and Human Affairs (1979) and Biology of Moral Systems (1988a), and Daly and Wilson's Sex, Evolution and Behavior (1983). Important texts like Alcock's Animal Behavior (1984), Krebs and Davies' Introduction to Behavioral Ecology (1981), and Trivers' Social Evolution (1985) approached behavior from a selectionist perspective.

Events of the past few years suggest that this growth is accelerating. Occasional conferences and scattered publications have offered glimpses of the growth of a conceptual, evolutionary approach to human lifetimes and behavior. In North $\Lambda$ merica, research has grown particularly rapidly at Harvard, UCLA, U.C. San Diego, University of Washington, Emory University, the University of Michigan, Northwestern University, and McMaster University. Faculty and graduate students at the last three universities met annually to exchange ideas from 1981-1987. The University of Michigan group was especially fortunate in receiving support from the University as a result of efforts by Billy Frye, Vice Provost for Academic Affairs and Professor of Biology. This made it possible to sponsor larger conferences in 1988 , and to fund preliminary research, something notably difficult in emerging and interdisciplinary fields.

The growing activity in and about the field of evolution and behavior can be viewed as an intellectual renaissance in which scholars in previously unconnected fields are exchanging ideas. Twenty-five years ago, the idea of "evolutionary" anthropology or "evolutionary" psychology would have been thought absurd; the various fields were often seen as both competitive, and (paradoxically) having little to offer each other. Now, because theo- 
retical advances have literally changed what we can see, evolutionary theory has become an intellectual center, a source of new ideas, in some ways a parallel to 15th century Italy. A thriving commerce of ideas is growing, as scholars from long-separated disciplines learn from each other, and find new ways of looking at problems and new questions to ask in their home fields. As they return to "home" departments, these new ideas may not always be welcome, but old dogmas are nonetheless questioned, and new ways of thinking, new questions, emerge. It is increasingly clear that the evolutionary paradigm will not "cannibalize"' the existing social and behavioral sciences; it offers instead an additional perspective that can integrate work in diverse disciplines.

\section{CURRENT WORK IN EVOLUTION AND HUMAN BEHAVIOR}

The excitement and cross-fertilization of diverse conceptual approaches are reflected by the papers in two recent meetings in Ann Arbor: the Evolution and Human Behavior Conference in April, 1988 (160 people, 80 presentations), and the Evolutionary Psychology and Psychiatry conference in October, 1988 ( 100 people, 47 presentations). One of the most exciting aspects of these meetings was the combination of an expanding range of topics and breadth of interest with an increasing precision of analysis in individual papers. Major themes in the two meetings included life history strategies (optimal allocation of somatic, mating, parental effort, including sexual selection, parent-offspring conflict, kin selection) $(\mathrm{n}=35)$; physiological phenomena (8); psychological phenomena (14); individual strategies such as language and speech (3); interindividual strategies (e.g., manipulation, hierarchy negotiation) (16); perspective papers (9); and societal phenomena, including politics (7), law (1), warfare and lethal conflict (2), music (1), and the evolution of culture (1). Some of these major foci are reviewed here. These categories are obviously somewhat artificial; for example, a paper like Laura Betzig's analysis of causes of conjugal dissolution could be indexed as familial, conflict, or life history strategies, etc.

\section{Life History Strategies}

This broad topic was a major focus of both meetings. Some analyses were done within an anthropological framework, using the evolutionary paradigm. Lee Cronk examined status and sex bias in parental investment among the Mukogodo; the Mukogodo have lower status than neighboring tribes, and tend to favor their daughters, as predicted by the Trivers-Willard (1973) hypothesis. Mark Flinn found that household composition affects female reproductive strategies in Trinidad. Michael Polioudakis presented several detailed analyses of prestige, marriage patterns, and kinship in southern 
Thailand. Napoleon Chagnon, back from the field only a few days, brought current information on his long-term study of the Yanomamö, perhaps the first anthropological study to take an evolutionary approach. William Irons. reporting on his long-term study of the Turkmen (another of the first to take an evolutionary approach), analyzed male and female life histories and reproductive competition in an evolutionary context. David Buss presented a cross-cultural analysis of sexual dimorphism in mating preferences. Randolph Nesse found support for the pleiotropic theory of senescence. as originally proposed by Williams.

Several papers focused on the inheritance of traits. Mark Ritchie presented a model of the interaction of cultural and natural selection, suggesting for the first time that, under certain conditions, the interaction may produce a mean phenotype at a different selective equilibrium from that produced by either force acting alone. Nancy Segal reported on characteristics of twins raised together and apart.

In fact, the entire spectrum of investment patterns was examined, including somatic effort (Gary Belovsky, Joan Lockard and K. Janelle VanCampen), mating effort (Monique Borgerhoff Mulder; David Buss and Lisa Dedden; James Donovan, Elizabeth Hill, and W. Janiowiak; Bruce Ellis and Donald Symons; Veronica Fiske; Ronald Immerman; Liisa Kyl-Heku and David Buss; Joseph Manson), parental effort and kin selection (Deborah Cowans, Krista Phillips, Phillipe Rushton, Irwin Silverman). Martin Smith analyzed wills as a form of parental and grandparental investment, and looked for ontogenetic shifts in investment predicted by theory. Margo Wilson and Martin Daly reviewed the interplay between paternity law and kinship theory. Pamela Wells and R. J. H. Russell analyzed kinship and the distribution of Christmas gifts. Denys DeCantanzaro offered an analysis of suicide in evolutionary perspective. Several papers in October focused on evolutionary origins of conflict between spouses and between parents and children. Presenters noted the contrast between this view and other perspectives that had much more difficulty explaining such conflicts. Another theme was the interpretation of personality differences as interpersonal strategies fine-tuned to the current environment.

\section{Psychological and Physiological Phenomena}

Michelle Surbey analyzed the social ecology of menarche, and C. M. Worthman examined the behavioral biology and significance of concealed ovulation. Charles Crawford and Judith Anderson, in several papers, analyzed the possible adaptive significance of anorexia nervosa, and Michael McGuire addressed the interactions of physiological mechanisms or "triggers" and patterns of helping. Stephen Heisel argued that the original function of blushing, probably thermoregulation, has been overlaid by an additional use as a signal. David Smillie proposed an evolutionary scenario, arising from the 
value of information, for the evolution of language. Willem de Winter focused on the adaptive function of emotions.

The shaping of emotions by natural selection was the topic of several papers in October: self-esteem (John Price), anxiety (Isaac Marks), mood (Leon Sloman and John Price, Russell Gardner), suffering (van Roojien), response to music (Richard Alexander), and emotions in general (Jay Frierman).

\section{Interactions and Conflict}

Many of the papers detailing the evolution of interactions focussed on mating effort, including intra- and intersexual conflicts of interest. David Buss and I isa Dedden analyzed the ways in which men and women subtly derrogated competitors to potential mates. Laura Betzig examined the causes of marital dissolution cross-culturally.

Some papers specifically examined open conflict at the group level. In April, Doug Jones reported that rates of homicide and warfare show a strong correlation with group size in pre-state societies. John Tooby and Leda Cosmides suggested that specific "Darwinian algorithms" or cognitive programs evolved to facilitate social coalitions, most likely in the context of intergroup aggression. In October, several papers again emphasized the power of an evolutionary approach to explain conflict, with an additional focus on deceptive strategies. The principle was applied at all levels: Offspring/parent patterns of manipulation, marital relationships, reciprocity relationships, psychotherapeutic relationships, and Western society as a whole.

\section{Societal Phenomena}

Whether societal phenomena are best analyzed as emergent properties, or sums of individual actions, was addressed in both meetings. In April, several papers focused on the evolution of political behavior: politics and aggression (Jesse Chanley), sex differences in political activities (Bobbi Low), reproductive success of political leaders (Laura Betzig), and politics in primates other than humans (Vincent Falger). Gary Johnson proposed an evolutionary model of the origins of governments. In the poster session, Richard Conner showed, with videos as well as posters, how male bottle-nosed dolphins compete in coalitions and "supercoalitions" for access to females.

Demographic phenomena were approached from an evolutionary perspective. Paul Turke tackled the problem of whether children's economic productivity can affect parents' desire for children, as has been proposed by several demographers. Bobbi Low analyzed resource control and men's reproductive success in 19 th century Sweden. In one of the few studies with data on male reproductive success in modern societies, Elizabeth Hill found a positive relationship between income and family size. 


\section{Artificial Intelligence and Cognitive Psychology}

A session on cognitive psychology and artificial intelligence in October provided a substantive and controversial focus. Cognitive psychology is quickly making links with artificial intelligence, and scholars in both fields are finding evolutionary theory useful in understanding the origins and functions of the mechanisms they study. The importance of looking for domain-specific, specialized information processors (Leda Cosmides) was a matter of general agreenent. Examples such as algorithnus for preferming certain chanacteristics in potential mates (Donald Symons, David Buss) and specialized capacities for analyzing reciprocity relationships were discussed.

\section{Applications}

In addition to theoretical papers, there are growing attempts to apply evolutionary theory to practical problems. The need for caution was addressed in several papers and in discussion. Some psychiatrists and lawyers, in particular, hope that an evolutionary approach can help to resolve some of the conceptual issues that have split their fields into factions. In April, Jack Beckstrom tackled the "is-ought" problem in law. In October, Alfonso Troisi applied classical ethological methods to patient behaviors to predict responsiveness to antidepressant agents. Charles Crawford and Judith Anderson presented their work on the evolutionary significance of anorexia nervosa. Work on the biology of mood has already been noted.

One of the farthest-reaching new efforts is the use of reciprocity theory to understand the origins of interpersonal and intrapsychic conflict. Kevin Kerber used this approach for marriage. Karen Norberg for parent-chi!d interactions, James Kennedy for patterns of interaction in group therapy, and Kalman Galanz for psychotherapy. Martin Daly and Margo Wilson tested alternative explanations of parent-offspring conflict. and concluded that available homicide data do not support the Freudian view. Papers by Alan Lloyd, Daniel Wilson and Jean Boulanger used evolutionary theory to reinterpret psychodynamic concepts. This diverse group of papers reflect a surge of attempts to clarify the conceptual problems that bedevil attempts to understand psychopathology. $\Lambda$ theme emerged from this work: much interpersonal conflict and apparent pathology may, in fact, be adaptive.

\section{Standards of Evidence and Perspectives in a Growing Field}

In April, Monique Borgerhoff Mulder reviewed the shift in emphasis in recent anthropological stu ties from simpler problems of foraging to more complex life history and reproductive issues. Jerome Barkow cautioned against just-so stories and urged rigor to avoid evolutionary theory as folk wisdom. In October, several papers argued that the study of mechanisms is essential in the developing field of evolutionary psychology, despite the difficulties 
(Don Symons, John Tooby, Leda Cosmides). Laura Betzig noted the difficulties of limiting work to that approach, as well as the benefits of studying reproductive success directly, and analyzing the current utility of behaviors for which mechanisms are not obvious.

These meetings, as well as recent publications, reflect the growing change in the broad field of evolution and human behavior from casual speculation to empirical tests, and from mutual enthusiasm to searching criticism. It remains difficult to formulate testable hypotheses, but much progress has been made. The current trend is to label speculation clearly and to specify how hypotheses can be tested. In any complex endeavor, it may be difficult to be solely inductive or solely deductive (e.g. Alexander 1988b), but it is important to be clear. Evolutionary studies of human behavior are still young, but we may be approaching the point at which findings may become clear and testable enough to serve as the foundation for future work.

\section{DIVERGENT MEMES, EMERGENT THEMES}

The breadth of the field of evolution and human behavior generates vigorous and useful disagreement. As an example, the conflicts surrounding brain/ mind mechanisms, mentioned above, are as yet unresolved. One group of scholars, including anthropologists and demographers, looks at trait-environment correlations, testing for patterns in reproductive success and inclusive fitness predictable from basic theory. Often these scholars seek to explain initially puzzling behaviors like altruism. They are also interested in current utility. Patterns such as adoption by cousins or female infanticide in high status families, for example, are predicted (and found) to increase reproductive success in specifiable conditions, and the presence of selective forces in shaping such behaviors is inferred. A strength of this approach is its ability to generate and test specific hypotheses using demographic data and comparative methods.

Another group, including many psychologists, argues that only mind/ brain mechanisms are suitable objects of evolutionary explanation, because these mechanisms have been directly shaped by natural selection, while behavior patterns generally have not. They would like to restrict study to adaptations, and to look at adaptive behaviors (behaviors that increase inclusive fitness) only when they can be connected to mechanisms.

Both groups envision mechanisms considerably more specific than the abstract logical algorithms that fueled much of the early work in artificial intelligence. Robert Hinde, in the keynote address for the April meeting, emphasized what may represent our best chance of advance: encouraging rigorous work at all levels, while recognizing explicitly the level at which work is done. 


\section{THE HUMAN BEHAVIOR AND EVOLUTION SOCIETY}

There are now collected works on topics such as evolutionary anthropology (Alexander and Tinkle 1978; Chagnon and Irons 1979; Betzig; Borgerhoff Mulder; and Turke 1988), infanticide (Hausfater and Hrdy 1984), optimal foraging in hunter-gatherers (Smith and Winterhalder 1981), and self-deception (Lockard and Paulhus 1988), works on human sexuality (Symons 1979), co-operation (Axelrod 1984, Axelrod and Hamilton 1981), and even texts which include evolutionary approaches to human behavior (Daly and Wilson 1983; Trivers 1985; Alcock 1978). Yet for many there remains a feeling of fragmentation. There has been no common forum for exchanging ideas.

As activity has grown over several years, so has the idea of forming a society to facilitate communication among those applying evolutionary theory to human behavior. Several people requested, in registering for the October conference, that time be set aside to consider plans for future meetings. All who attended the conference were invited to participate in an organizational meeting. The idea of forming an "evolutionary psychology and psychiatry" group was quickly discarded. Many participants were from other disciplines: biology, anthropology, artificial intelligence, philosophy, law and others-and all recognized the great benefit of interdisciplinary conferences. Consequently, the group decided to form an organization explicitly welcoming all researchers using evolutionary theory to understand human behavior at all levels.

William Hamilton was unanimously elected first President of the organization, in recognition of his central role in revising evolutionary theory in ways that made the advances of the past two decades possible, and because his work has influenced so many different disciplines. In a second meeting, members of a Steering Committee were nominated, and there was an extended discussion of the name of the group; after considering many possibilities, the group decided on the "Human Behavior and Evolution Society." The intent was to find a name acceptable to all those working in the diverse fields in which evolutionary theory may be of some use in understanding human behavior, even at the cost of specificity and elegance.

Information about the new Society and the Annual Meeting may be obtained from The Human Behavior and Evolution Society, \% Northwestern University, 1310 Hinman, Evanston. IL, 60208-1310, or by calling (312) 4915402 .

\section{REFERENCES}

Alcock. J. Animal behavior: An evolutionary approach. 3rd cd. Sunderland. MA: Sinauer Associates. 1979.

Alexander, R.D. Daminism and human affairs. Seattle: Univ. Washington Press. 1979.

- The evolution of social behavior. Annual Review of Ecology and Systematics 5: 325-383, 1974. 
- The biology of moral systems. Chicago: Aldine deGruyter, 1988a.

Evolutionary approaches to human behavior: What does the future hold? In Human reproductive behavior: A Darwinian perspective. L. Betzig and Borgerhoff M. Mulder (Eds.). Cambridge: Cambridge University Press, 1988.

- - and D.W. Tinkle (eds.). Natural selection and social behavior. New York and Concord: Chiron Press, 1981.

Axelrod, R. The evolution of cooperation. New York: Basic Books. 1984.

Axelrod, R. and Hamilton, W.D. The evolution of cooperation. Science 211: 1390-1396, 1981.

L. Betzig, M. Borgerhoff Mulder, and P. Turke (Eds.). Human reproductive behavior: A Darwinian perspective. Cambridge: Cambridge University Press, 1988.

N.A. Chagnon and W. Irons (Eds.) Evolutionary biology and human social behavior: An anthropological perspective. Boston: Duxbury Press, 1979.

Daly, M. and Wilson, M. Sex, evolution, and behavior. 2nd ed. Boston, MA: Willard Grant, 1983.

Dawkins, R. The selfish gene. New York, Oxford University Press, 1976.

Dawkins, R. The blind watchmaker. New York: Norton, 1986.

Hamilton, W.D. The genetical evolution of social behavior. Journal of Theoretical Biology 7 : $1-52,1964$.

Hausfater, G. and Hrdy, S.B. Infanticide. New York: Aldine de Gruyter, 1984.

Krebs, I.R., and Davies, N.B. An introdurtion to hehavioral ecology. Sunderland, MA: Sinauer, 1981.

Lockard, J.S., and Paulhus, D.L. Self-deception: An adaptive mechanism? Englewood Cliffs, New Jersey: Prentice Hall, 1988.

Lumsden, C., and Wilson, E.O. Genes, mind, and culture. Cambridge, MA: Harvard Univ. Press, 1981.

Maynard Smith, J., and Price, G. The logic of animal conflict. Nature, Lond. 246: 15-18, 1973.

Smith, E.A. and Winterhalder, B. Hunter-gatherer foraging strategies: Ethnographic and archaeological analyses. Chicago: University of Chicago Press, 1981.

Symons, D. The evolution of human sexuality. New York: Oxford University Press, 1979.

Trivers, R.L. The evolution of reciprocal altruism. Quarterly Review of Biology 46: 35-57, 1971.

Trivers, R.L. Parental investment and sexual selection. In Sexual selection and the descent of man, B. Campbell (Ed.). Chicago: Aldine, 1972.

Trivers, R.L. Parent-offspring conflict. American Zoologist 14: 249-264, 1974.

Trivers, R.L. Social evolution. Menlo Park, CA: Benjamin/Cummings, 1985.

Trivers, R.L., and Willard, D.E. Natural selection of parental ability to vary the sex ratio of offspring. Science 179: 90-92, 1973.

Williams, G.C. Adaptation and natural selection. Princeton, NJ: Princeton University Press, 1966.

Wilson. E.O. Sociobiology: the new synthesis. Cambridge, MA: Harvard University Press, 1975. 